\title{
Antimicrobial Polyethylene through Melt Compounding with Quaternary Ammonium Salts
}

\author{
Fernanda F. Rossetti, ${ }^{1}$ Konstantin Siegmann, ${ }^{1}$ Joachim Köser, ${ }^{2}$ \\ Irene Wegner, ${ }^{2}$ Ismail Keskin, ${ }^{2}$ Götz Schlotterbeck, ${ }^{2}$ and Martin Winkler ${ }^{1}$ \\ ${ }^{1}$ Institute of Materials and Process Engineering, School of Engineering, Zurich University of Applied Sciences (ZHAW), \\ 8400 Winterthur, Switzerland \\ ${ }^{2}$ Institut für Chemie und Bioanalytik, Hochschule für Life Sciences, Fachhochschule Nordwestschweiz, 4132 Muttenz, Switzerland \\ Correspondence should be addressed to Martin Winkler; martin.winkler@zhaw.ch
}

Received 2 March 2017; Accepted 6 April 2017; Published 30 April 2017

Academic Editor: Nabil Ibrahim

Copyright (C) 2017 Fernanda F. Rossetti et al. This is an open access article distributed under the Creative Commons Attribution License, which permits unrestricted use, distribution, and reproduction in any medium, provided the original work is properly cited.

Selected mono- and bicationic quats were compounded with polyethylene. The physicochemical surface properties, leaching behavior, and antibacterial activity of such modified samples were investigated. Contact angle measurements and fluorescein binding assays showed the presence of quaternary ammonium groups at the surface. After storing the samples in $50^{\circ} \mathrm{C}$ warm water for 30 days, several were still antimicrobially active. No correlation between the number of exposed $\mathrm{N}^{+}$head groups after leaching and the antibacterial activity was observed. There is however a qualitative correlation of the antibacterial activity with the contact angles and surface concentrations of $\mathrm{N}^{+}$before leaching/storing in warm water.

\section{Introduction}

Ship hulls [1], food packaging [2], and medical devices [3] are examples of objects needing surfaces on which microorganisms cannot proliferate. Therefore, considerable effort was put into the development of antimicrobial paints [4], coatings [5], and surface modifications [6]. Two approaches have been realized. The first is to incorporate a biocide into the base material or coating which is slowly set free, such as silver [7]. Silver ions are released from the surface into the water where they develop their biocidal properties. Such leaching coatings have, however, severe drawbacks. They have a limited life span because the biocide is eventually used up, and the water is contaminated with potentially hazardous compounds. Finally, the emergence of resistant strains has been observed. A nonleaching, permanent biocidal surface is therefore preferred. In the second approach, this is accomplished by binding a biocide to the polymer via a covalent bond [8]. Quaternary ammonium compounds (quats) can have biocidal properties and attempts to immobilize quats onto surfaces have been ample $[9,10]$. However, the methods used to attach quats at the surface are mostly tedious and thus inconvenient. This holds especially true for polyethylene as the substrate. Polyethylene consists of carbon-carbon and carbon-hydrogen bonds only and therefore is inert and unreactive. Very drastic methods are required to chemically modify polyethylene surfaces. UV-light induced radical [11] and sextet [12] reactions can be employed and, indeed, have been used to attach quats to polyethylene surfaces [13]. For large scale production, however, the application of UV-light is inconvenient. Also, hidden surfaces are only hardly accessible to UV-light. Therefore, a simple yet permanent and cheap method for immobilizing quats on polyethylene is in demand.

Melt compounding of small amounts of a biocidal polymer with polyethylene has shown producing a composite whose surface is antimicrobial. However, the biocidal polymer used was based on amino substituted methacrylate and did not contain quaternary ammonium moieties [14].

Quats are incompatible with polyethylene and therefore mixtures should segregate. Hence, some of the quats might migrate to the surface of the melt. If the quat contains a hydrocarbon residue which is miscible with the 
polyethylene matrix, the quat is expected to migrate to the air/melt interface, sticking the miscible hydrocarbon residue into the polyethylene and the charged groups out of the matrix. Such behavior was observed previously with other amphiphilic molecules [15]. It was shown, for example, that polyethylene glycol-block-polyethylene copolymers provide polyethylene with anticalcification features [16]. Compounds of polyethylene with appropriate quats should therefore selforganize, enriching the quats at the surface, pointing the quaternary ammonium head out of the polyethylene, and finally anchoring the quat with at least one long hydrocarbon chain in the polymer. Such compounds have to fulfill two main requirements. First, they have to be indeed active, that is, show antimicrobial behavior. Second, the effect should be permanent and not due to leaching of the quats. While the first prerequisite is relatively simple to demonstrate, the second is more demanding. The quats are not bound to the polyethylene by chemical bonds; weak Van-Der-Waals forces hold them in place instead. However, although being weak, Van-Der-Waals forces scale with the length of the anchoring hydrocarbon chain, and a long enough chain should retain the quat, preventing it from leaching.

In this work, selected mono- and bicationic quats (biquats) were compounded with polyethylene. The antimicrobial activity of several such modified PE samples was demonstrated and the presence of quaternary ammonium groups at the surface was confirmed. The samples were stored in $50^{\circ} \mathrm{C}$ warm water for 30 days, after which they were still antimicrobially active. The leaching behavior of the quats into the water was investigated using High Performance Liquid Chromatography/Mass Spectrometry (HPLC/MS).

\section{Materials and Methods}

Quaternary ammonium compounds $\mathbf{1}$ and $\mathbf{3}$ (see mono- and bifunctional quaternary ammonium salts tested in this study, Figure 1) were purchased from TCI Europe (Zwijndrecht, Belgium). Quats 2, 4, and 5 and all other chemicals were obtained from Sigma-Aldrich (Buchs, Switzerland) and used without further purification.

Polyethylene of raised temperature resistance (DOWLEX 2388 PE-RT) was obtained from Dow (Edegem, Belgium) in form of pellets. Prior to use, the pellets were ground to powder with an ultracentrifugal mill (ZM1, Retsch, Haan, Germany) cooled with liquid nitrogen. The PE-RT powder was mixed with the quats in a Turbula tumbling mixer (W. A. Bachofen AG, Basel, Switzerland) for $1 \mathrm{~h}$ prior to being extruded in a Process 11 parallel twin screw extruder (Thermo Scientific, Waltham, MA, USA) equipped with a slit die (slit: $1 \times 20 \mathrm{~mm}$ ). The rotation speed of the screws was $125 \mathrm{rpm}$ and the applied temperature ramp ranged from $180^{\circ} \mathrm{C}$ at the feeder to $230^{\circ} \mathrm{C}$ at the die. Typically, $65 \mathrm{~g}$ of PE-RT mixed with $1-5 \mathrm{wt}-\%$ of quats was extruded to obtain approximately $4 \mathrm{~m}$ of sample, the first $1.5 \mathrm{~m}$ of which was discarded.

Biquats 6-9 were synthesized according to Figure S1 in the Supplementary Material, available online at https://doi .org/10.1155/2017/2823604. 1,20-Dibromoeicosane and 1,30dibromotriacontane were prepared following literature procedures [17].
High Resolution Electrospray Ionization Mass Spectra were acquired at the Laboratory for Organic Chemistry, ETH Zurich, Switzerland.

2.1. Contact Angle Measurements. The contact angle of a sessile droplet of water on the PE-quat blends was measured with a Drop Shape Analyzer DSA100 (Krüss GmbH, Hamburg, Germany). A droplet of $6 \mu \mathrm{L}$ Millipore water was deposited at a speed of $60 \mu \mathrm{L} \mathrm{min}^{-1}$ and its shape was fitted with a LaplaceYoung procedure to determine the contact angle. For each data point, three spots were measured and the average and standard deviation were calculated.

2.2. Leaching of the Quats into Water. HPLC-MS (LC 1200/ MS Trap XCT, Agilent, Santa Clara, CA, United States) was used to determine the amount of quats leaching into water from the quat-PE samples. The column was a HALO RP-Amide $(2.1 \times 50 \mathrm{~mm}, \varnothing 2.7 \mu \mathrm{m})$ and the eluents used were as follows: (A) water : acetonitrile $95: 05+0.1 \%$ formic acid, (B) acetonitrile: water 95:5 + 0.1\% formic acid, and (C) isopropanol $+0.1 \%$ formic acid. The flow rate was $0.4 \mathrm{~mL} \mathrm{~min}^{-1}$, the oven temperature $35^{\circ} \mathrm{C}$, and the injection volume $1 \mu \mathrm{L}$. The mass spectrometer was in the multiple reaction monitoring electrospray ionization (MRM-ESI) mode, at a temperature of $350^{\circ} \mathrm{C}$ and with a gas flow of $8 \mathrm{~L} \mathrm{~min}^{-1}$.

In the first experiment, samples with a total area of $100 \mathrm{~cm}^{2}$ and a weight of $3.6-4.8 \mathrm{~g}$ were placed in $110 \mathrm{~mL}$ Millipore water for 30 days at $50^{\circ} \mathrm{C}$. After 3, 6, 10, 20, and 30 days an aliquot of $1 \mathrm{~mL}$ water was taken and analyzed by HPLC-MS. To ensure that leaching does not stop merely due to the development of an equilibrium between the surface and the bulk water, a further experiment was performed, where samples with a total area of $\sim 25 \mathrm{~cm}^{2}$ and a weight of $0.8-1.2 \mathrm{~g}$ were placed in $5 \mathrm{~mL}$ Millipore water at $50^{\circ} \mathrm{C}$. In this case, though, the water was fully exchanged after the removal of each aliquot at the $3 \mathrm{rd}, 6 \mathrm{th}, 10 \mathrm{th}, 20 \mathrm{th}$, and 30th day mark.

2.3. Agar Diffusion Test. A Kirby-Bauer type agar diffusion test was used as an alternative method to evaluate the release of quats from the PE matrix. Cutouts of quat-modified PE $(\sim 0.5 \times 1 \mathrm{~cm})$, both fresh and after one month of storage in water at $50^{\circ} \mathrm{C}$, were incubated overnight at $37^{\circ} \mathrm{C}$ on agar plates swabbed with $S$. aureus and subsequently inspected to assess if a zone of growth inhibition was induced around the sample.

\subsection{Determination of the Surface Concentration of Quaternary} Ammonium Ions. $2 \times 1 \mathrm{~cm}$ cutouts from extruded samples were placed for $10 \mathrm{~min}$ in $3 \mathrm{~mL}$ of a $1 \mathrm{wt}$ - $\%$ fluorescein solution, rinsed with water and excess fluorescein desorbed for $1 \mathrm{~h}$ in Millipore water. Subsequently the samples were immersed for $2 \mathrm{~h}$ in $3 \mathrm{~mL}$ of a $0.1 \mathrm{wt}-\%$ solution of trimethylstearylammonium chloride (2) to completely remove the surfaceadsorbed fluorescein. After that, $0.9 \mathrm{~mL}$ of this solution was mixed with $0.1 \mathrm{~mL}$ of a $100 \mathrm{mM}$ phosphate buffer solution at pH 8.0 and analyzed in a Lambda 2 UV-VIS spectrometer (Perkin Elmer, Waltham, MA, USA) to obtain the fluorescein concentration through $c=A /(\varepsilon \cdot l)$, where $A$ is the absorbance 
<smiles>CCCCCC[N+](C)(C)c1ccccc1</smiles>

Benzyldimethylstearylammonium chloride (1)<smiles>C[N+](C)(C)c1ccccc1</smiles>

Trimethylstearylammonium chloride (2)<smiles>CCCCCCCCCC[N+](C)(C)c1ccccc1</smiles>
$\mathrm{Cl}^{-}$ Dimethyldistearylammonium chloride (3)

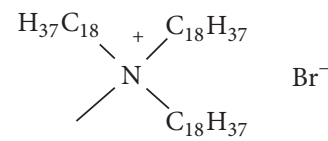

Methyltristearylammonium bromide (4)

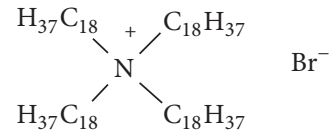<smiles>OCCCCCCCCCCO</smiles>

6<smiles>C[N+](C)(C=O)c1ccccc1</smiles><smiles>OCCCCCCCCCCCCCCCCCO</smiles>

7<smiles>OCCCCCCCCCCCCCCCCCCCCCCCCCO</smiles>

8<smiles>[R]CCOCCOCCOCCOCCOCCOCCOCC[R]</smiles>

9<smiles></smiles>

Tetrastearyl-

ammonium bromide (5)

FIGURE 1: Mono- and bifunctional quaternary ammonium salts tested in this study. Ts ${ }^{-}$is tosylate, $\mathrm{CH}_{3}\left(\mathrm{C}_{6} \mathrm{H}_{4}\right) \mathrm{SO}_{3}{ }^{-}$.

of the solution, $\varepsilon$ the extinction coefficient $\left(27.931 \mathrm{mM}^{-1} \cdot \mathrm{cm}^{-1}\right.$ for our system), and $l$ the path length.

2.5. Fluorescence Based Antimicrobial Activity Assays. The antimicrobial activity of selected modified PE samples against gram-positive and gram-negative bacterial species (S. aureus, E. coli, and P. aeruginosa) was determined in contact with a bacterial suspension for $16 \mathrm{hrs}$ followed by a conventional dead/live staining procedure (LIVE/DEAD ${ }^{\circledR}$
BacLight $^{\mathrm{TM}}$ Bacterial Viability Stain, Invitrogen ${ }^{\mathrm{TM}}$, Thermo Scientific, Waltham, MA, USA) of the surface associated bacteria. Bacteria were grown in nutrient broth (Carl Roth $\mathrm{GmbH}+\mathrm{Co}$. KG, Karlsruhe, Germany) until $\mathrm{OD}_{600}=0.6$, collected by centrifugation, and resuspended in the same volume of a synthetic medium without glucose [18] or filter-sterilized tap water. A drop of the suspension was incubated on the modified PE samples in a humid chamber. Following overnight incubation the bacteria not in direct 
contact with the surface were removed by two times of short dipping in tap water and the surface-attached bacteria were stained with a fluorescent dead/live staining procedure applying membrane permeable (syto green, Invitrogen) and impermeable (propidium iodide, Invitrogen) DNA binding stains. The analysis of the samples was done by confocal laser scanning microscopy (CLSM, Olympus, Hamburg, Germany). Bacterial survival in tap water samples showed certain variations and only experiments where at least 50\% of the bacteria survived in the suspensions on pure PE were evaluated.

\section{Results and Discussion}

3.1. Monofunctional Quaternary Ammonium Salts. The left column of Figure 1 lists the monofunctional quats used as antimicrobial additives for polyethylene in this study. The quats have methyl, stearyl, and/or benzyl groups bound to the nitrogen. It is thought that at least one long stearyl $\left(\mathrm{C}_{18} \mathrm{H}_{37}\right.$, n-octadecyl) group anchors the quat in the matrix.

3.2. Bifunctional Quaternary Ammonium Salts. The right column of Figure 1 shows bifunctional quats (biquats), which were synthesized by a double nucleophilic substitution reaction, as described in Figure S1 in the Supplementary Material. Bifunctional means that two quaternary ammonium moieties are connected by a long hydrocarbon or polyethylene oxide spacer.

The hydrocarbon linkers in biquats 6-8 were chosen because of their compatibility with polyethylene; however, such linkers are difficult to obtain. $\mathrm{C}_{20} \mathrm{H}_{40} \mathrm{Br}_{2}$ and $\mathrm{C}_{30} \mathrm{H}_{60} \mathrm{Br}_{2}$, starting materials for biquats 7 and 8, respectively, are not commercially available and have to be synthesized by Kolbe synthesis [17].

Biquat 9 contains a polyoxyethylene linker which is readily prepared from, for example, polyethylene glycol (PEG) $400\left(400 \mathrm{~g} \cdot \mathrm{mol}^{-1}\right.$ is the average molecular weight of the PEG). Commercially available PEG is a mixture of different molecules having varying chain lengths. PEG (400) consists of molecules comprising 5 to 12 ethylene oxide $\left(\mathrm{EO}, \mathrm{C}_{2} \mathrm{H}_{4} \mathrm{O}\right)$ units; a chain with 8 EOs is most abundant (shown in Figure 1).

The reasoning for the utilization of biquats as opposed to monoquats is shown in Figure 2. During segregation of the two ammonium head groups to the surface, the linker may entangle with polyethylene chains (Figure 2(b)). This anchors the molecule mechanically in the matrix, in addition to the anchoring given by the Van-Der-Waals forces, possibly inhibiting leaching.

However, such entanglement is hard to demonstrate by the analytical techniques available. Nevertheless, we interpret the absence of leaching - combined with durable antimicrobial properties of the sample-as indication of entanglement and firm anchoring.

3.3. Anchoring of Quats in PE and Influence on the Surface Properties. Since quats have a polar group, they are very well soluble in water. Therefore, when a quat-modified PE sample is immersed in water, the quats will easily transfer to the aqueous phase if they are not anchored to the surface in a sufficiently strong manner. Through analysis of such water it is possible to ascertain if, and in which amount, quats leach out of the PE matrix. Table 1 shows the results of HPLC/MS analysis of the water in which the modified PE samples had been immersed. In a first experiment, the samples were immersed in $50^{\circ} \mathrm{C}$ warm water for one month, during which successive aliquots were removed every few days (Table $1(\mathrm{a})$ ). In a second experiment, the $50^{\circ} \mathrm{C}$ warm water was replaced several times with fresh water over the duration of a month (Table 1(b)). In both cases, only biquats 6, 7, and 9 were found to leach, while the monoquats 1-5 were below the detection limit of our measurement protocol $\left(0.020 \mu \mathrm{g} \mathrm{mL}^{-1}\right)$. The detection limit corresponds to $\sim 0.2$ quat molecules leached out per $\mathrm{nm}^{2}$ of sample in the experiment without water exchange and $\sim 0.03$ quats $\mathrm{nm}^{-2}$ for the experiment with water exchange, indicating that a minor amount of leaching cannot be excluded. The very high leaching of biquat 9 is likely due to the incompatibility of PEG with polyethylene [16], making it difficult to compound biquat 9 into PE. This approach was nevertheless attempted to ascertain if PEG chains could be used as alternative, longer spacers (thus more likely to form loops), since the educts for the synthesis of biquats 7 and 8 (1,20-dibromoeicosane and 1,30-dibromotriacontane) are difficult to synthesize in large amounts.

It is conceivable that biquat 9 forms small droplets in the matrix instead of a homogeneous compound. The droplets would then dissolve in water during the leaching test.

In the experiment with no water exchange, the amount of quats in solution increased quickly within the first 1-2 days and then remained constant. This can indicate either that the quats only leach initially and then stop, or that after some time an equilibrium is reached between the quats in solution and those at the surface. A frequent exchange of water helps to distinguish between these two scenarios. Table 1(b) reveals that for quat 6 the leaching indeed stops after 3 days. Moreover, if the amount of quat 6 in the PE is reduced to $1 \mathrm{wt}-$ $\%$ no leaching at all is detected. The case of quat 7 is different: here the leaching continues (even though slightly reduced after the third day) over the entire investigated period of 30 days. This is true even if the amount of quat in the compound is reduced to 3 and $1 \mathrm{wt}-\%$, respectively. This indicates that a longer hydrocarbon chain connecting the two ammonium groups does not provide a firmer anchoring of biquats in the $\mathrm{PE}$. In general, the use of biquats per se does not seem to offer an improved anchoring to the PE matrix. Compared to monoquats, biquats have two charged ammonium groups per molecule instead of one, which may reduce their miscibility and lead to the segregation of biquats at the surface of the compound before entanglements with the PE chains can occur (indeed, while extruding it was observed that it is possible to compound up to $20 \mathrm{wt}-\%$ of monoquat 1 in the $\mathrm{PE}$, while for biquat 6 the limit is already reached at $5 \mathrm{wt}-\%)$.

It is interesting to note how the number of quat molecules leaching out of the samples per $\mathrm{nm}^{2}$ of surface is clearly lower for the experiment with water exchange compared to 


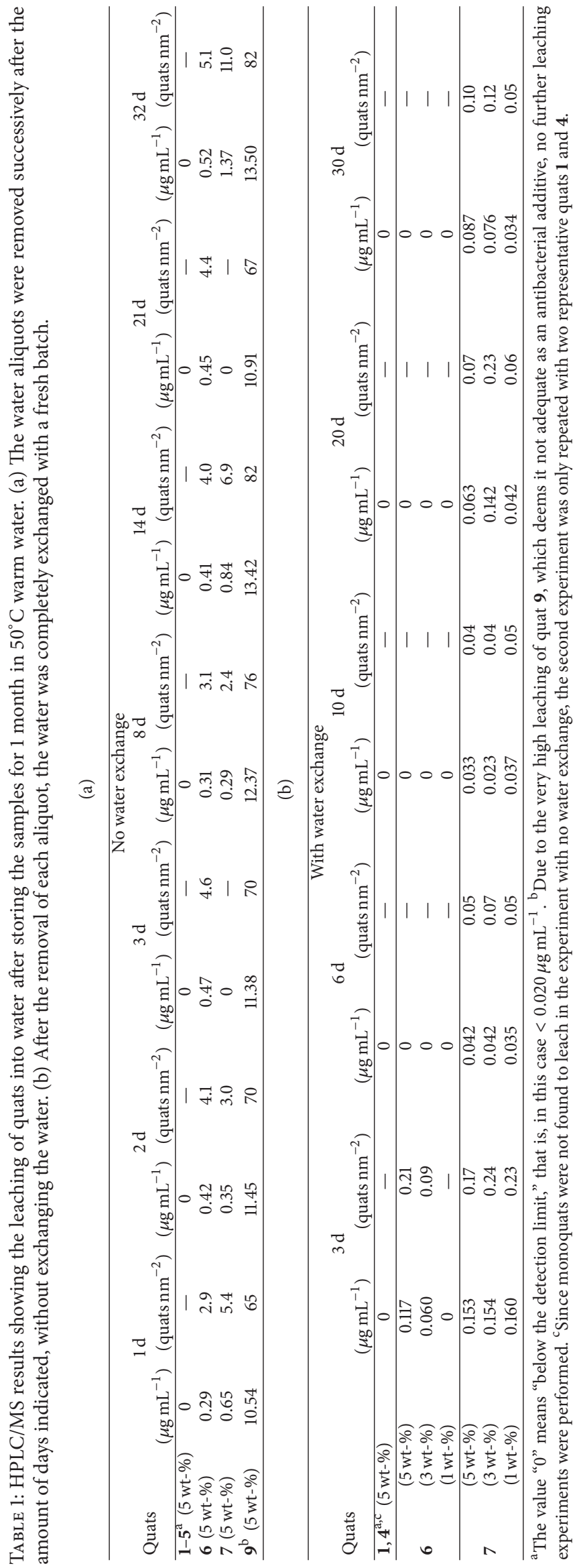




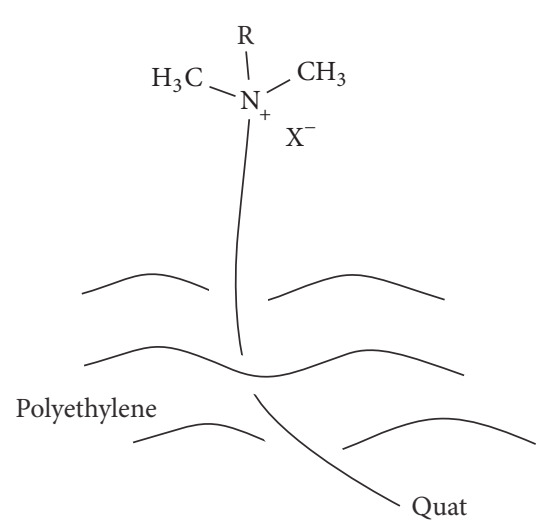

(a)

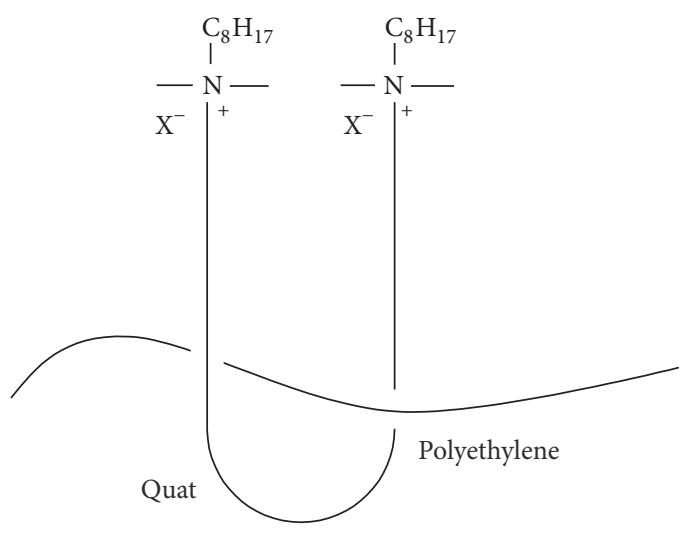

(b)

FIGURE 2: Schematic representation of mono- and biquats. (a) Monoquat anchored in polyethylene via its hydrocarbon chain. The quaternary ammonium group is at the surface. (b) Biquat entangled with a polyethylene chain. Both quaternary ammonium groups face the surface of PE.

the one without exchange. This is to be expected for aliquots withdrawn after several exchanges of water; however, in the case of the very first aliquot, the results should be comparable. The fact that this is not the case may be due to different leaching kinetics, caused by different volume to surface ratios $\left(\sim 100 \mathrm{~cm}^{2}\right.$ in $110 \mathrm{~mL}$ versus $\sim 25 \mathrm{~cm}^{2}$ in $5 \mathrm{~mL}$, i.e., 5 times less water per surface area in the case with water exchange), or due to comparatively large measurement errors close to the detection limit of the technique.

The leaching of quats was also investigated with an indirect method, the agar diffusion test. After placing the quat-modified PE samples on a carpet of bacteria cultured on agar we noted if a zone of inhibition of bacterial growth could be seen around the samples. Such a zone of inhibition indicates that a bacteriotoxic substance has diffused out of the sample and a larger inhibition zone points to either greater leaching or a stronger antibacterial activity of the leached substance. Table 2 shows the results obtained for (i) freshly extruded samples and (ii) samples that had been left leaching in water at $50^{\circ} \mathrm{C}$ for one month. Strikingly, monoquats $\mathbf{1}$, 2, and 3 do show an inhibition zone before leaching, even though no leaching was observed by HPLC/MS. For 1 and 2 the inhibition zone remains even after leaching for one month in water. This apparent contradiction can be due to several factors; for example, the agar diffusion test might be more sensitive than HPLC/MS, detecting even trace amounts of quats. On the other hand, in the agar diffusion test the samples are placed on a nutrient and ion-rich surface instead of being immersed in Millipore water, which may influence the leaching mechanism. Additionally, substances other than quats may be leaching out of the samples and killing the bacteria on the agar plate, such as additives already present in the PE or decomposition products of the quats that are formed at the high extrusion temperatures (up to $230^{\circ} \mathrm{C}$; for instance, the decomposition of quat $\mathbf{1}$ gives rise to the formation of benzyl chloride, data not shown).

It is noteworthy that before leaching the inhibition zone of biquat $\mathbf{6}$ is much larger than that of other biquats $\mathbf{7}$ and $\mathbf{9}$, even though HPLC/MS has shown that biquat 9 has by far
TABLE 2: Results of the agar diffusion test. The plus signs indicate the presence of a zone of inhibition around a piece of quat-modified PE that was placed on a carpet of bacteria cultured on agar.

\begin{tabular}{lcccccccc}
\hline & \multicolumn{10}{c}{ Quats } \\
& 1 & 2 & 3 & 4 & 5 & 6 & 7 & 9 \\
\hline Before leaching & + & ++ & + & - & - & +++ & + & ++ \\
After leaching & + & ++ & - & - & - & - & + & - \\
\hline
\end{tabular}

the highest leaching and that biquats $\mathbf{6}$ and $\mathbf{7}$ initially have a comparable leaching rate (Table 1). This could be attributed to a higher antibacterial activity of biquat 6 (see Table 3). However, no inhibition zone is observed for biquat $\mathbf{6}$ after 30 days of water storage (Table 2), in accordance with the observation by HPLC/MS that its leaching stops after 3 days (Table 1).

The physicochemical surface properties of freshly prepared, quat-modified PE samples and of the same samples after one month of leaching were investigated by (i) determining the surface density of positively charged $\mathrm{N}^{+}$ atoms by a colorimetric method and (ii) measuring the contact angle of a water droplet. The first technique allows for obtaining information on a microscopic scale, while the contact angle measurements reflect the surface properties on a macroscopic scale. As shown in Figure 3, for fresh samples (before leaching) containing 5\% quat, there is a clear decrease of the contact angle of the extruded samples as a function of the relative amount of nitrogen in the quat molecule. In particular, the strongest effect is observed for biquats 6 to 9 , suggesting that, in this case, the two nitrogen head groups at the two ends of the molecule are both exposed on the sample surface. On the other hand, quats 4 and 5 (carrying 3 and 4 stearyl chains, resp.) even lead to a higher contact angle than measured for the PE matrix, suggesting that some of the side chains stick out of the surface, while the remaining ones anchor the quat in the PE. When the amount of quats is reduced from $5 \%$ to $3 \%$ and $1 \%$ the trend to a lower contact angle with increasing $\mathrm{N}^{+}$content remains the same, but the 


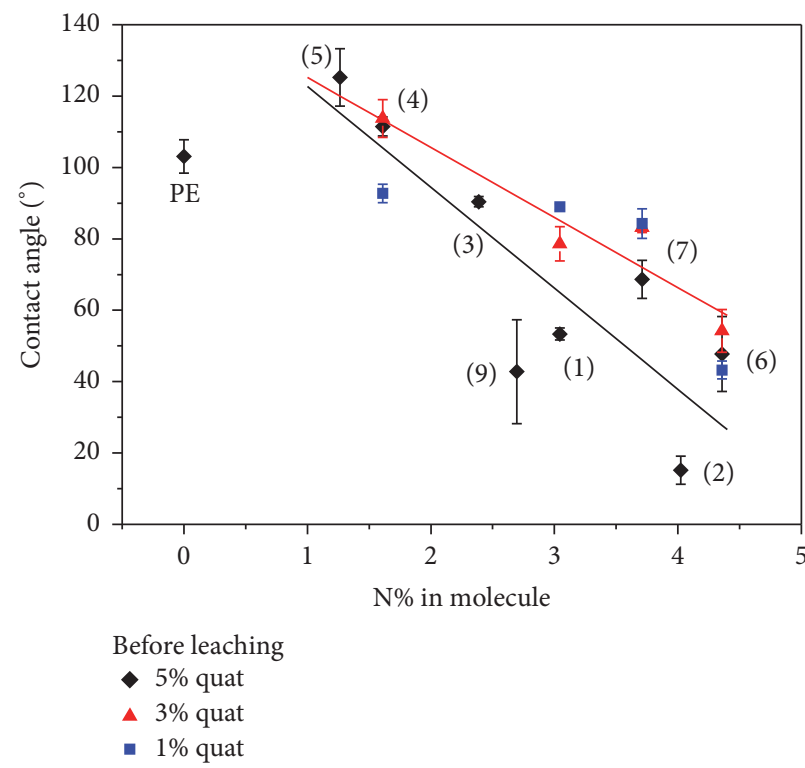

(a)

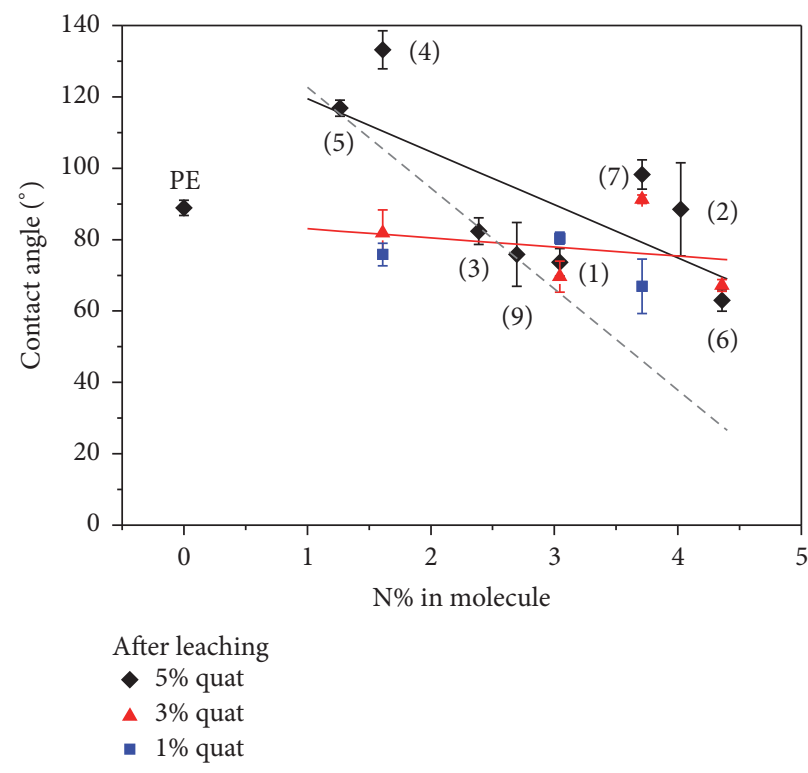

(b)

Figure 3: Contact angle of the quat-modified PE samples as a function of N-content in the quat molecule. (a) Freshly extruded samples. The black and red solid lines are the linear regression of the data sets with 5\% quat and 3\% quat, respectively, and are only meant to guide the eye. (b) Samples that were leached in water for one month. The solid lines are linear regressions of the corresponding data sets. The dashed line in panel (b) (after leaching) corresponds to the solid black line in panel (a) (before leaching).

effect is weaker, as can be seen from the decreased slope of the trend line (cf. the black and red lines in Figure 3(a)).

After leaching in water, the effect of quats is still present, but in an attenuated form, as visible from the flatter slopes in Figure 3(b) (the trend line before the leaching - the black line in Figure 3(a)-is replicated in Figure 3(b) as a dashed line). This indicates that quats that were not firmly anchored to the surface were washed away and is consistent with the leaching observed in particular for the biquats. It is notable that the contact angle of pure PE decreases by ca. $10^{\circ}$ after storage in water, possibly due to the washing out of hydrophobic processing additives.

To quantify how many quat molecules stick out on the surface of the extruded samples before and after leaching, an indirect colorimetric method was used [19, 20]. Fluorescein is a fluorescent compound that binds to ammonium ions in a 1:1 ratio [20], allowing us to determine the surface concentration of $\mathrm{N}^{+}$head groups. Figure 4(a) shows the results obtained for modified PE samples containing $5 \mathrm{wt}-$ $\%$ quats before and after leaching: before leaching it is visible how, at a higher relative amount of nitrogen in the pure quat (above ca. 2\%), the surface concentration of $\mathrm{N}^{+}$ increases linearly with the amount of $\mathrm{N}$ in the quat molecule. These results are consistent with the contact angle results shown in Figure 3(a). Quat 2 constitutes an exception to the linear relationship, most probably due to the fact that the removal of bound fluorescein from the samples prior to detection by UV/VIS was done by using an aqueous quat 2 solution, possibly leading to an equilibrium of the fluorescein bound to quat 2 on the surface and quat 2 in solution.
A similar linear increase of the surface concentration of $\mathrm{N}^{+}$, albeit less pronounced, is observed also for the extruded samples containing $3 \%$ and $1 \%$ quats, again reproducing the same trend observed with the contact angle measurements (Figure 3(b)).

Below $2 \% \mathrm{~N}$ in the pure quat, the surface concentration of $\mathrm{N}^{+}$remains constant in the range $0.5-1 \mathrm{~N}^{+} \mathrm{nm}^{-2}$, which is the same value obtained from unspecific adsorption of fluorescein on unmodified PE. Since the detection limit of the UV/VIS spectrometer was $0.05 \mu \mathrm{mol} \mathrm{L}^{-1}$, which for our samples would correspond to $0.2 \mathrm{~N}^{+} \mathrm{nm}^{-2}$, the very low values obtained for quats $\mathbf{4}$ and $\mathbf{5}$ are not due to the detection limit but indicate that very little $\mathrm{N}^{+}$is exposed at the surface. This does not necessarily mean, however, that more quat molecules are not present at the surface. Considering that quats 4 and $\mathbf{5}$ carry 3 and 4 stearyl chains, respectively, and that PE modified with quat 4 is antibacterial (see Table 3), it is possible that one or more of the stearyl chains shield the $\mathrm{N}^{+}$, preventing the fluorescein to adsorb to it. This is consistent with the contact angle results, showing a contact angle higher than that of PE in the presence of quats $\mathbf{4}$ and $\mathbf{5}$ (Figure 3).

The effect of leaching on the number of exposed $\mathrm{N}^{+}$ atoms was very pronounced: for all samples the measured surface concentration after leaching was in the range $0.3-2.5 \mathrm{~N}^{+} \mathrm{nm}^{-2}$, that is, in the same range as, or only slightly above, the amount of unspecific adsorption detected for pure $\mathrm{PE}\left(0.5 \pm 0.2 \mathrm{~N}^{+} \mathrm{nm}^{-2}\right)$. Since several of the samples were still antibacterial after leaching, it appears that already the presence of $1-2 \mathrm{~N}^{+} \mathrm{nm}^{-2}$ is sufficient to kill bacteria adhering to the surface (see Figure 4 (after leaching) and Table 3). 


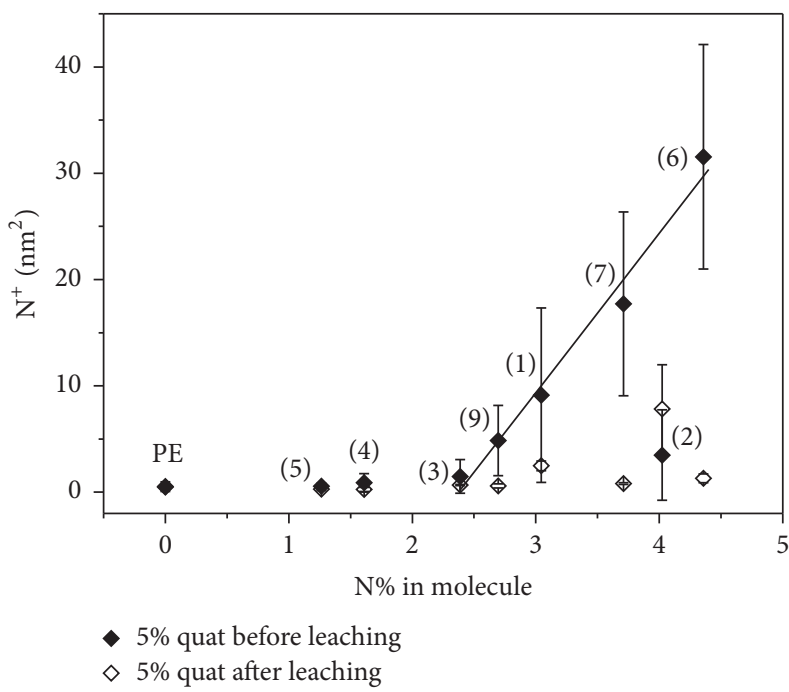

(a)

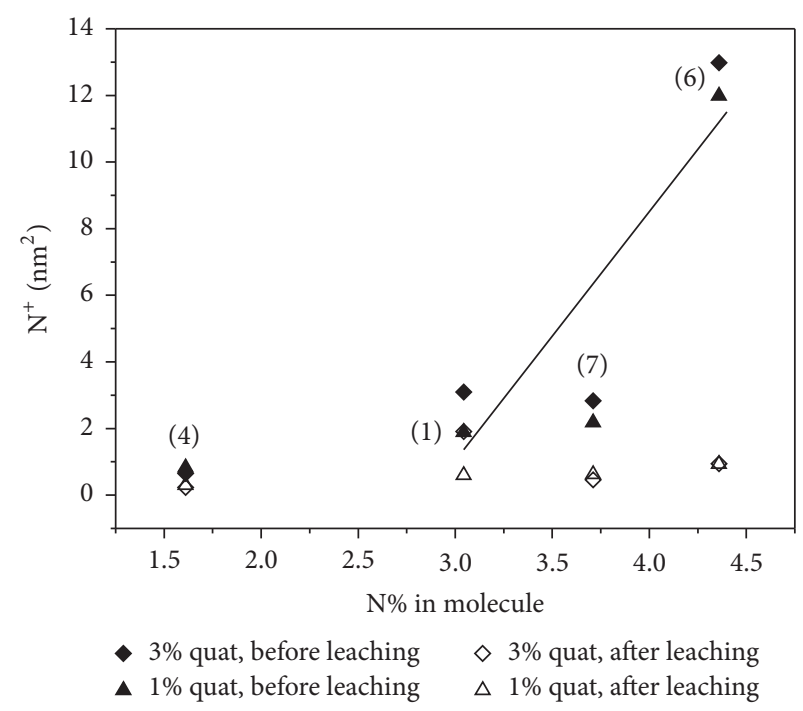

(b)

FIGURE 4: Surface concentration of $\mathrm{N}^{+}$head groups as a function of $\mathrm{N}$-content in the quat molecule. (a) Results before and after leaching for PE samples containing 5 wt- $\%$ quat. (b) PE samples containing 1 and 3 wt- $\%$ quat, respectively.

TABLE 3: Antibacterial activity of modified PE samples containing $5 \mathrm{wt}-\%$ quat (after leaching) against S. aureus, E. coli, and $P$. aeruginosa. Bacterial survival in tap water was variable; therefore only experiments where at least $50 \%$ of the bacteria survived in the suspension on pure PE were considered for this table. ++: most bacteria are dead; +: proportion of dead bacteria clearly increased compared to PE reference; +/-: different results with different samples; -: proportion of dead bacteria not increased compared to PE reference.

\begin{tabular}{lccc}
\hline & \multicolumn{3}{c}{ Antibacterial activity } \\
Quats $^{\mathrm{a}}$ & S. aureus & E. coli & P. aeruginosa \\
\hline $\mathbf{1}$ & ++ & ++ & n.a. \\
$\mathbf{2}$ & - & n.a. & n.a. \\
$\mathbf{3}$ & - & - & n.a. \\
$\mathbf{4}$ & ++ & $+/-$ & ++ \\
$\mathbf{5}$ & - & n.a. & - \\
$\mathbf{6}$ & ++ & ++ & ++ \\
7 & + & + & ++ \\
9 & + & - & ++ \\
\hline
\end{tabular}

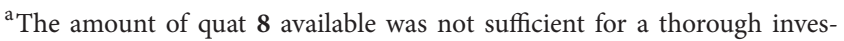
tigation; however, in preliminary experiments it was found to have good antibacterial activity against $S$. aureus.

Threshold surface densities in a similar range have been reported previously as necessary to kill bacteria by contact [21-23].

Comparing the number of quats per unit area measured by the fluorescein method (Figure 4) with the number of quat molecules leaching out of the samples per day per unit area (Table 1), it strikes the eye that in the case of biquat 9 many more quat molecules leached out during the first day than are present on the surface ( 65 quats $\mathrm{nm}^{-2}$ versus $2.5 \pm 1.6$ quats $\mathrm{nm}^{-2}$ ), indicating either that there has been diffusion of quats from the bulk to the surface, or that there were regions with aggregates of quats that did not mix with the PE matrix.

Finally, the influence of the quats on the mechanical properties of the PE matrix was investigated by performing tensile tests on cutouts of the modified, extruded samples (see Figure S2 in the Supplementary Material). The influence of quats was rather small, only in the case of $5 \%$ quat 7 did the modified PE sample become significantly more brittle.

3.4. Antibacterial Activity of Quat-Modified PE Surfaces. The antibacterial activity of the quats used in this work was investigated by live/dead staining of bacterial strains of $S$. aureus, E. coli, and $P$. aeruginosa incubated overnight on the modified PE samples. Table 3 summarizes the results obtained for samples containing $5 \%$ quats. In all cases the samples had been left leaching in water at $50^{\circ} \mathrm{C}$ for one month. The most antibacterial quats were found to be quat 1 (carrying a benzyl group), quat 4 (carrying three stearyl chains), biquat 6 (with a $\mathrm{C}_{12}$ spacer), and biquat 7 (with a $\mathrm{C}_{20}$ spacer).

If the antibacterial activity of the quats is compared to the physicochemical properties of the sample surfaces, one can observe that there is no correlation between the number of exposed $\mathrm{N}^{+}$head groups after leaching and the antibacterial activity, since all quats exhibit similar surface densities in the range $0.5-2.5 \mathrm{~N}^{+} \mathrm{nm}^{-2}$ (Figure 4 ). The values of the contact angles after leaching do not seem predictive of the antibacterial activity either, due to the large scattering of the data (Figure 3(b)). There is however a qualitative correlation of the antibacterial activity with the contact angles and surface concentrations of $\mathrm{N}^{+}$before leaching: the quats exposing more $\mathrm{N}^{+}$(roughly $>3 \mathrm{~N}^{+} \mathrm{nm}^{-2}$ ) are more likely to be antibacterial. This might indicate that the samples exposing more $\mathrm{N}^{+}$before leaching are still exposing more $\mathrm{N}^{+}$ than the nonantibacterial samples even after leaching but that 
this difference is too small in magnitude to be detected with the methods used in this work. For instance, the nonspecific adsorption of fluorescein to the samples may be larger than the intersample differences in the surface concentration of $\mathrm{N}^{+}$. On the other hand, the contact angle measurements are sensitive to factors such as the surface roughness of the samples, again introducing large errors in the results.

A further explanation on why the differences in the antibacterial activity are not detected by surface sensitive techniques may be that those samples that are still antibacterial after leaching may lose some of the quats sticking out of the surface but still possess further quats a few $\AA$ below the surface. Such quats would not be able to exert their bacteria-killing effect via the often assumed mechanism of penetration and disruption of the bacterial wall and/or membrane. However, as recently postulated by Asri et al. [24], other mechanisms also play a role in bacterial death at the solid-liquid interface, such as the adhesion strength between a positively charged, quat-modified substrate and the negatively charged bacterial surface. A similar mechanism is observed for biocidal peptides and biocidal copolymers used to disinfect bulk solutions, where a synergistic effect of the cationic and hydrophobic parts of those molecules is needed to kill bacteria [25].

This mechanism may also explain why quat 4 is antibacterial even though the number of detected $\mathrm{N}^{+}$is small and the contact angle is high: the three stearyl chains of this quat may arrange in a way that the $\mathrm{N}^{+}$is shielded, but an interaction with approaching bacteria is still possible and strong enough to lead to bacterial death.

\section{Conclusions}

In this article the physicochemical surface properties, leaching behavior, and antibacterial activity of extruded polyethylene samples compounded with several mono- and biquats were investigated. For freshly extruded samples before leaching the contact angle of water was found to decrease and the surface concentration of $\mathrm{N}^{+}$to increase, as a function of the relative amount of nitrogen in the quat molecules.

Leaching of the samples in $50^{\circ} \mathrm{C}$ warm water was observed for the biquats, while no leaching of the monoquats could be detected. The biquat with the shortest spacer chain $\left(\mathrm{C}_{12}\right)$ was found to stop leaching within 3 days, as confirmed by both HPLC/MS and agar diffusion test. The biquats with longer spacers continued leaching during the entire measurement period of one month.

After the leaching step, the decrease of the contact angle with increasing $\mathrm{N}$ was still visible, albeit to a much lesser degree. On the other hand, the surface density of $\mathrm{N}^{+}$was now found to be in the same range for all quats $\left(0.5-2.5 \mathrm{~N}^{+} \mathrm{nm}^{-2}\right)$, independently of the relative amount of N. Since some of the quats still possessed an antibacterial activity-that is, quat $\mathbf{1}$ (carrying a benzyl group), quat $\mathbf{4}$ (carrying three stearyl chains), biquat 6 (with a $\mathrm{C}_{12}$ spacer), and biquat 7 (with a $\mathrm{C}_{20}$ spacer)-while others did not, one can conclude that there is no correlation between the number of exposed $\mathrm{N}^{+}$head groups after leaching and the antibacterial activity. There seems however to be a qualitative correlation of the antibacterial activity with the contact angles and surface concentrations of $\mathrm{N}^{+}$before leaching: the quats exposing more $\mathrm{N}^{+}$(roughly $>3 \mathrm{~N}^{+} \mathrm{nm}^{-2}$ ) are more likely to be antibacterial.

The mechanical properties of polyethylene (Young's modulus and elongation at break) were not affected by compounding with the quats, except for an increase in brittleness when adding at least $5 \%$ of the biquat with a longer spacer chain (biquat $7, \mathrm{C}_{20}$ ).

\section{Conflicts of Interest}

The authors declare that there are no conflicts of interest regarding the publication of this paper.

\section{Acknowledgments}

The authors would like to acknowledge the Commission for Technology and Innovation (CTI) of the Swiss Federal Council for financial support.

\section{References}

[1] D. M. Yebra, S. Kiil, C. E. Weinell, and K. Dam-Johansen, "Effects of marine microbial biofilms on the biocide release rate from antifouling paints-a model-based analysis," Progress in Organic Coatings, vol. 57, no. 1, pp. 56-66, 2006.

[2] X. Li, Y. Xing, Y. Jiang, Y. Ding, and W. Li, "Antimicrobial activities of $\mathrm{ZnO}$ powder-coated PVC film to inactivate food pathogens," International Journal of Food Science and Technology, vol. 44, no. 11, pp. 2161-2168, 2009.

[3] D. Roe, B. Karandikar, N. Bonn-Savage, B. Gibbins, and J.B. Roullet, "Antimicrobial surface functionalization of plastic catheters by silver nanoparticles," Journal of Antimicrobial Chemotherapy, vol. 61, no. 4, pp. 869-876, 2008.

[4] E. N. Makarewicz, A. V. Shiichuk, and I. D. Syrotyns'ka, "Quaternary ammonium salts as antimicrobial additives to water-dispersible paints," Russian Journal of Applied Chemistry, vol. 84, no. 5, pp. 888-891, 2011.

[5] D. Park, J. Wang, and A. M. Klibanov, “One-step, painting-like coating procedures to make surfaces highly and permanently bactericidal," Biotechnology Progress, vol. 22, no. 2, pp. 584-589, 2006.

[6] J. C. Tiller, S. B. Lee, K. Lewis, and A. M. Klibanov, "Polymer surfaces derivatized with poly(vinyl-N-hexylpyridinium) kill airborne and waterborne bacteria," Biotechnology and Bioengineering, vol. 79, no. 4, pp. 465-471, 2002.

[7] S. Silver, L. T. Phung, and G. Silver, "Silver as biocides in burn and wound dressings and bacterial resistance to silver compounds," Journal of Industrial Microbiology and Biotechnology, vol. 33, no. 7, pp. 627-634, 2006.

[8] E.-R. Kenawy, S. D. Worley, and R. Broughton, "The chemistry and applications of antimicrobial polymers: a state-of-the-art review," Biomacromolecules, vol. 8, no. 5, pp. 1359-1384, 2007.

[9] L. Ferreira and A. Zumbuehl, "Non-leaching surfaces capable of killing microorganisms on contact," Journal of Materials Chemistry, vol. 19, no. 42, pp. 7796-7806, 2009. 
[10] R. Nigmatullin and F. Gao, "Onium-functionalised polymers in the design of non-leaching antimicrobial surfaces," Macromolecular Materials and Engineering, vol. 297, no. 11, pp. 10381074, 2012.

[11] T. Wang, E. T. Kang, K. G. Neoh, K. L. Tan, and D. J. Liaw, "Surface modification of low-density polyethylene films by UVinduced graft copolymerization and its relevance to photolamination," Langmuir, vol. 14, no. 4, pp. 921-927, 1998.

[12] L.-H. Liu and M. Yan, "Perfluorophenyl azides: new applications in surface functionalization and nanomaterial synthesis," Accounts of Chemical Research, vol. 43, no. 11, pp. 1434-1443, 2010.

[13] V. P. Dhende, S. Samanta, D. M. Jones, I. R. Hardin, and J. Locklin, "One-step photochemical synthesis of permanent, nonleaching, ultrathin antimicrobial coatings for textiles and plastics," ACS Applied Materials and Interfaces, vol. 3, no. 8, pp. 2830-2837, 2011.

[14] G. Seyfriedsberger, K. Rametsteiner, and W. Kern, "Polyethylene compounds with antimicrobial surface properties," European Polymer Journal, vol. 42, no. 12, pp. 3383-3389, 2006.

[15] D. G. Walton, P. P. Soo, A. M. Mayes et al., "Creation of stable poly(ethylene oxide) surfaces on poly(methyl methacrylate) using blends of branched and linear polymers," Macromolecules, vol. 30, no. 22, pp. 6947-6956, 1997.

[16] K. Siegmann, R. Sterchi, R. Widler, and M. Hirayama, "Lime repellent polyethylene additives," Journal of Applied Polymer Science, vol. 129, no. 5, pp. 2727-2734, 2013.

[17] F. L. M. Pattison, J. B. Stothers, and R. G. Woolford, "Anodic syntheses involving $\omega$-monohalocarboxylic acids," Journal of the American Chemical Society, vol. 78, no. 10, pp. 2255-2259, 1956.

[18] G. Fuchs and H. G. Schlegel, Allgemeine Mikrobiologie: Begründet von Hans-Günter Schlegel, 8. vollständig überarbeitete und erweiterte Auflage edition, Thieme, 2006.

[19] J. Huang, H. Murata, R. R. Koepsel, A. J. Russell, and K. Matyjaszewski, "Antibacterial polypropylene via surface-initiated atom transfer radical polymerization," Biomacromolecules, vol. 8, no. 5, pp. 1396-1399, 2007.

[20] J. W. Ledbetter Jr. and J. R. Bowen, "Spectrophotometric determination of the critical micelle concentration of some alkyldimethylbenzylammonium chlorides using fluorescein," Analytical Chemistry, vol. 41, no. 10, pp. 1345-1347, 1969.

[21] S. Roest, H. C. Van Der Mei, T. J. A. Loontjens, and H. J. Busscher, "Charge properties and bacterial contact-killing of hyperbranched polyurea-polyethyleneimine coatings with various degrees of alkylation," Applied Surface Science, vol. 356, pp. 325-332, 2015.

[22] R. Kügler, O. Bouloussa, and F. Rondelez, "Evidence of a chargedensity threshold for optimum efficiency of biocidal cationic surfaces," Microbiology, vol. 151, no. 5, pp. 1341-1348, 2005.

[23] H. Murata, R. R. Koepsel, K. Matyjaszewski, and A. J. Russell, "Permanent, non-leaching antibacterial surfaces-2: how high density cationic surfaces kill bacterial cells," Biomaterials, vol. 28, no. 32, pp. 4870-4879, 2007.

[24] L. A. T. W. Asri, M. Crismaru, S. Roest et al., "A shape-adaptive, antibacterial-coating of immobilized quaternary-ammonium compounds tethered on hyperbranched polyurea and its mechanism of action," Advanced Functional Materials, vol. 24, no. 3, pp. 346-355, 2014.

[25] E. Marie, S. Sagan, S. Cribier, and C. Tribet, "Amphiphilic macromolecules on cell membranes: from protective layers to controlled permeabilization," Journal of Membrane Biology, vol. 247, no. 9-10, pp. 861-881, 2014. 

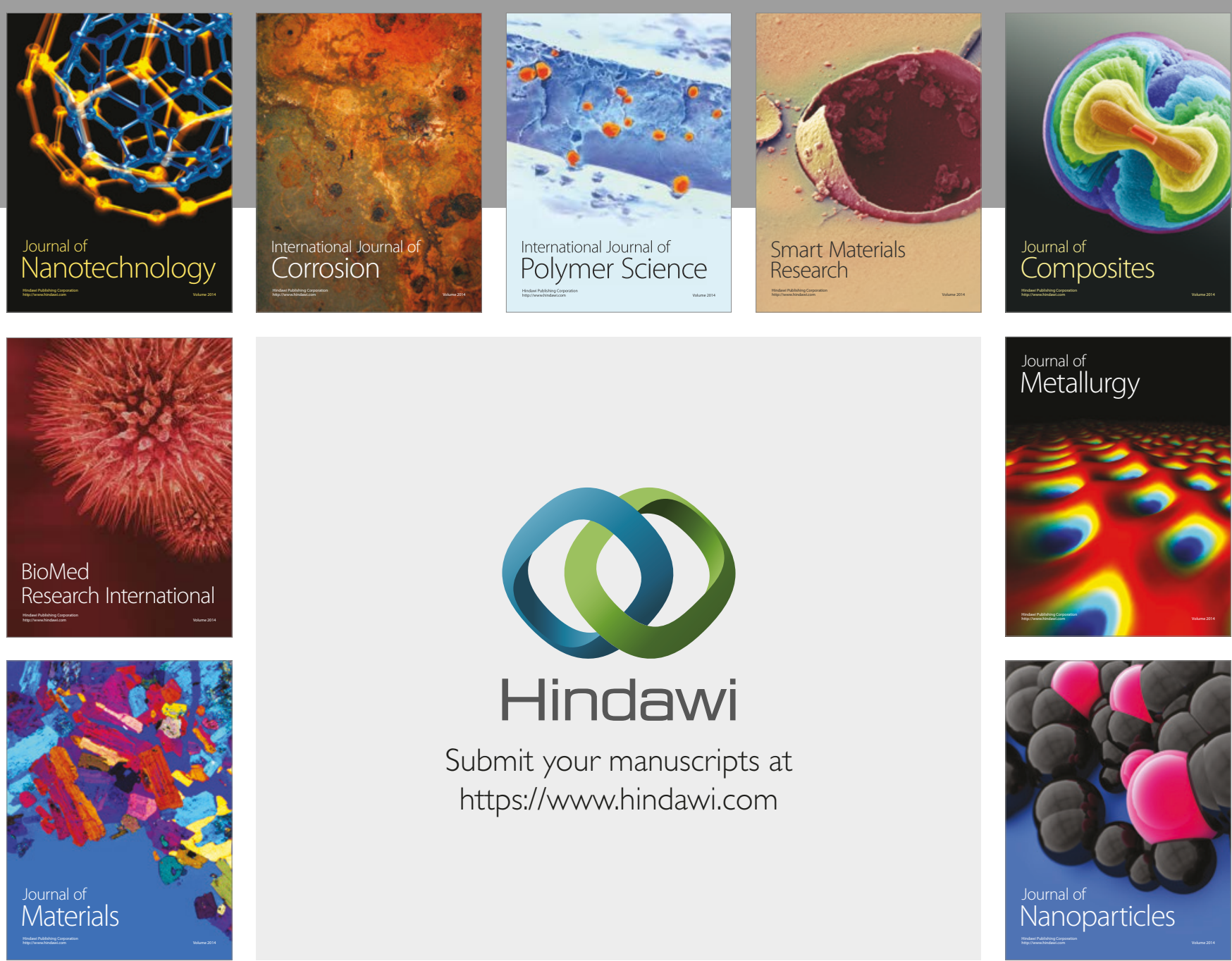

\section{Hindawi}

Submit your manuscripts at

https://www.hindawi.com
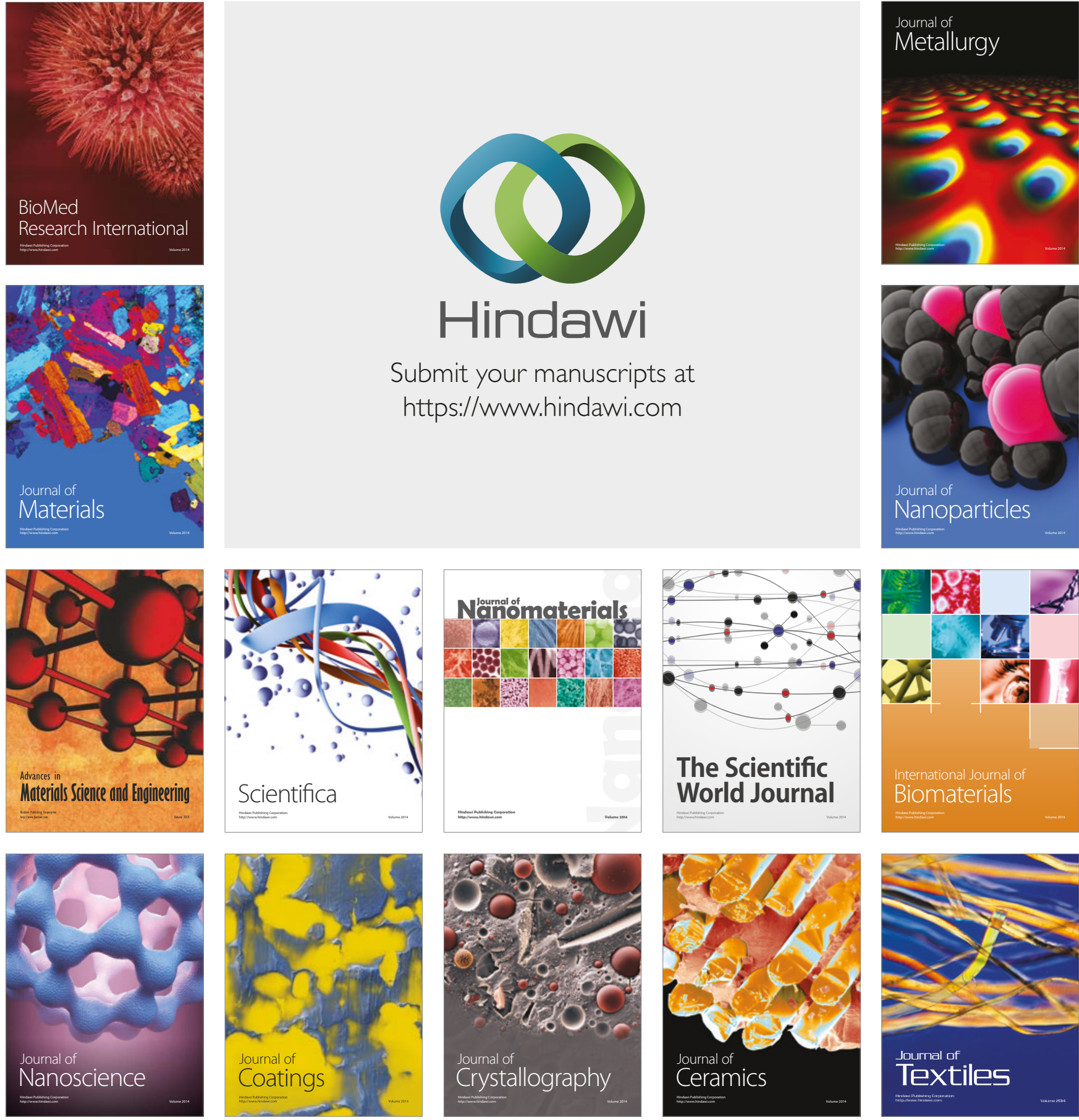

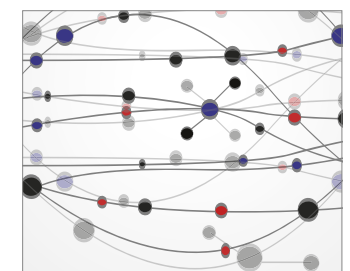

The Scientific World Journal
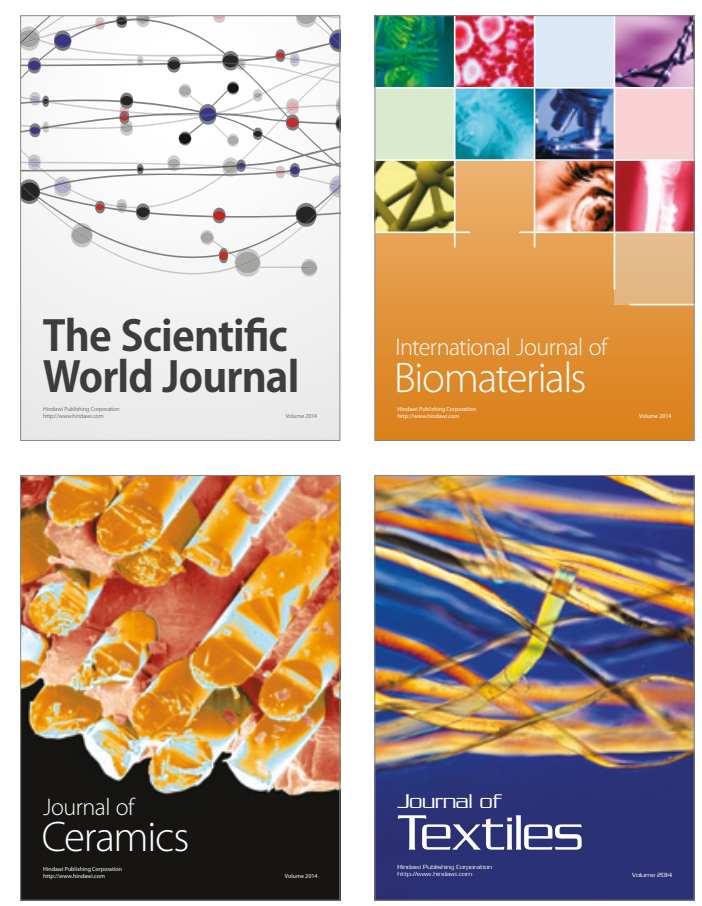